\title{
Concept Map versus Matrix Note Taking: Achievement, Attitude, and Note-Taking Effects
}

\author{
Junrong Lu \\ Kenneth A. Kiewra \\ Yiling Zhang \\ Department of Educational Psychology \\ University of Nebraska-Lincoln \\ Lincoln, NE 68588-0345, USA
}

\begin{abstract}
College students were trained in how to record concept map notes, matrix notes, or conventional (control group) notes. Students then read a brief text using their respective note-taking method in preparation for fact, relationship, and concept test items that were administered immediately or following a review period. It was predicted that matrix note takers would achieve most, because matrix notes are more computationally efficient than map notes. Although matrix notes did not prove superior to map notes in terms of achievement, results suggested several problems with map note taking. First, conventional note takers achieved more on relationship items than map note takers, but not matrix note takers. Second, map note takers had more incomplete notes and lower quality notes than matrix note takers. Last, concept map note takers rated their notes lower in effectiveness, ease of construction, enjoyability, and likelihood of future use compared to matrix note takers.
\end{abstract}

Keywords: Note taking, concept map, matrix

\section{Introduction}

Students often experience difficulty learning from text because information is usually presented in blocks (paragraphs) and lines (sentences) that obscure text relationships. For example, the Figure 1 planets text obscures important relationships such as: As planets move farther from the sun, their revolution time increases, and their orbit speed decreases. Conventional student note taking is usually not helpful for text learning because students usually record notes in a linear list-like fashion that also obscures text relationships (Kiewra et al., 1991; Jairam\& Kiewra, 2010).

\section{Figure 1 Planets Text}

\section{Planets}

Mercury is an inner planet and is 36 million miles from the sun. Its revolution time around the sun is 3 months. Its orbit speed (miles/second) is 30 . Its diameter (miles) is 3,000 . Mercury has a rocky surface.

Venus is an inner planet and is 67 million miles from the sun. Its revolution time around the sun is 8 months. Its orbit speed (miles/second) is 22 . Its diameter (miles) is 8,000 . Venus has a rocky surface.

Earth is an inner planet and is 93 million miles from the sun. Its revolution time around the sun is 1 year. Its orbit speed (miles/second) is 19. Its diameter (miles) is 8,000. Earth has a rocky surface.

Mars is an inner planet and is 142 million miles from the sun. Its revolution time around the sun is 2 years. Its orbit speed (miles/second) is 15 . Its diameter (miles) is 4,000 . Mars has a rocky surface.

Jupiter is an outer planet and is $\mathbf{4 8 3}$ million miles from the sun. Its revolution time around the

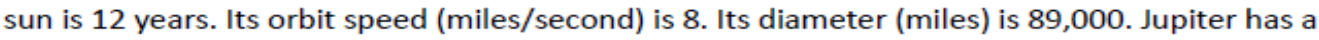
slushy surface.

Saturn is an outer planet and is $\mathbf{8 8 6}$ million miles from the sun. Its revolution time around the sun is 30 years. Its orbit speed (miles/second) is 6 . Its diameter (miles) is 75,000 . Saturn has a slushy surface.

Uranus is an outer planet and is 2 billion miles from the sun. Its revolution time around the sun is 84 years. Its orbit speed (miles/second) is 4 . Its diameter (miles) is 32,000 . Uranus has a slushy surface.

Neptune is an outer planet and is 3 billion miles from the sun. Its revolution time around the sun is 165 years. Its orbit speed (miles/second) is 3 . Its diameter (miles) is 31,000 . Neptune has 
Graphic organizers (GO) can help students see and learn text relationships more quickly (Robinson \& Skinner, 1996) and effectively (Jairam \& Kiewra, 2010) than learning from text alone. GOs are visual representations that display text information in spatial arrangements such as outlines, hierarchies, sequences, matrices, and concept maps (Jiang \&Grabe, 2007; Katayama et al., 1997; Kiewra, 2012).

Theoretically, GOs are effective because they are computationally efficient (Larkin \& Simon, 1987). They extract important information from text and position it so that related ideas are close together and in spatial patterns that make relationships immediately apparent (Kauffman \& Kiewra, 2010). For example, examine the Figure 2 planets matrix and see how quickly you can spot the relationships mentioned previously, plus these: Inner planets, relative to outer planets, are smaller and rockier.

\section{Figure 2 Planets Matrix}

\begin{tabular}{|c|c|c|c|c|c|c|c|c|}
\hline & \multicolumn{8}{|c|}{ Planets } \\
\hline & \multicolumn{4}{|c|}{ Inner } & \multicolumn{4}{|c|}{$\frac{\text { Outer }}{1}$} \\
\hline & Mercury & Venus & Earth & Mars & Jupiter & Saturn & Uranus & Neptune \\
\hline $\begin{array}{l}\text { Miles from } \\
\text { the Sun: }\end{array}$ & $\begin{array}{l}36 \\
\text { million }\end{array}$ & $\begin{array}{l}67 \\
\text { million }\end{array}$ & $\begin{array}{l}93 \\
\text { million }\end{array}$ & $\begin{array}{l}142 \\
\text { million }\end{array}$ & $\begin{array}{l}483 \\
\text { million }\end{array}$ & $\begin{array}{l}886 \\
\text { million }\end{array}$ & $\begin{array}{l}2 \\
\text { billion }\end{array}$ & $\begin{array}{l}3 \\
\text { billion }\end{array}$ \\
\hline $\begin{array}{l}\text { Revolution Time } \\
\text { Around the Sun: }\end{array}$ & 3 months & 8 months & 1 year & 2 years & 12 years & 30 years & 84 years & 165 years \\
\hline $\begin{array}{l}\text { Orbit Speed } \\
\text { (Miles/Second): }\end{array}$ & 30 & 22 & 19 & 15 & 8 & 6 & 4 & 3 \\
\hline Diameter (Miles): & 3,000 & 8,000 & 8,000 & 4,000 & 89,000 & 75,000 & 32,000 & 31,000 \\
\hline Surface: & Rocky & Rocky & Rocky & Rocky & Slushy & Slushy & Slushy & Slushy \\
\hline
\end{tabular}

Not all GOs are created equal. Some GOs are more computationally efficiently than others. For example, studies have shown that matrices are superior to outlines (Kauffman \& Kiewra, 2010; Kiewra et al., 1988; Kiewra et al., 1992; Robinson \& Schraw, 1994), some matrices are superior to other matrices (Jairam et al., 2011), and thathierarchies are superior to outlines(Robinson \&Kiewra, 1995).

Two of the most widely known and investigated graphic organizers are concept map and matrix. However, there is a lack of scientific research comparing which is more effective. Therefore, the present study compared their effectiveness.

\subsection{Concept Map}

Concept maps are top-down GOs that represent important concepts (called nodes), using boxes or circles, and relationships between these nodes, using links (Novak, 1998; Novak \& Gowin,1988; Kiewra, 2012). For example, the planets concept map in Figure 3 displays planet names (e.g., Mars) and their details (e.g., 2 years) as nodes. It displays the relationships between nodes using links, such as the link orbits, which joins the nodes Earth and 19 miles/second to convey that the orbit speed of Earth is 19 miles/second.

Some research indicates that concept maps aid text learning. Such was the case when students were given completed concept maps (Horton et.al., 1993; Qarareh, 2010), given incomplete concept mapsto complete (Willerman\& Mac Harg, 1991), or trained to create their own concept maps (Asan, 2007; Grave \&Swart, 1997). Concept maps have proven effective for both fact (Hall \& O'Donnell, 1996; Hall et al., 1992) and relationship learning (Lehmanet al., 1985; Schmid \&Telaro, 1990).

Other research indicates that concept maps do not aid text learning, especially when students create or fill-in concept maps (Nesbit \&Adesope, 2006; Romero et al., 2017),becauseconcept maps are difficult to create and study (Eppler, 2006). When students create concept maps, the resulting maps are often poorly organized and are missing important nodes or links (Ason, 2007; Nicoll et al., 2001).Students have also reported that the construction of concept maps was demanding and that it was difficult to identify the important concepts, organize them, and create links (Swart, 1994). In the few studies where students were able to create high-quality concept maps, intensive training was necessary and took three weeks or more to complete (Ason, 2007; Jegede et al., 1990), or map creation involved using special software unavailable to most students (Anderson-Inman \&Zeith, 1993; Ason, 2007; Eppler, 2006). 


\subsection{Matrix}

A matrix is a two-dimensional cross-classification table or chart (Jairamet et al., 2011). Its column and row structure make it especially applicable for comparing information both within and across rows (Jairam et al., 2011; Kiewra, 2012). A matrix, like that in Figure 2, contains three parts: topics on top (e.g., Mercury), categories down the left side (e.g., miles from the sun), and details within the matrix cells at the intersection of topics and categories (e.g., 36 million).

\section{Figure 3 Planets Concept Map}

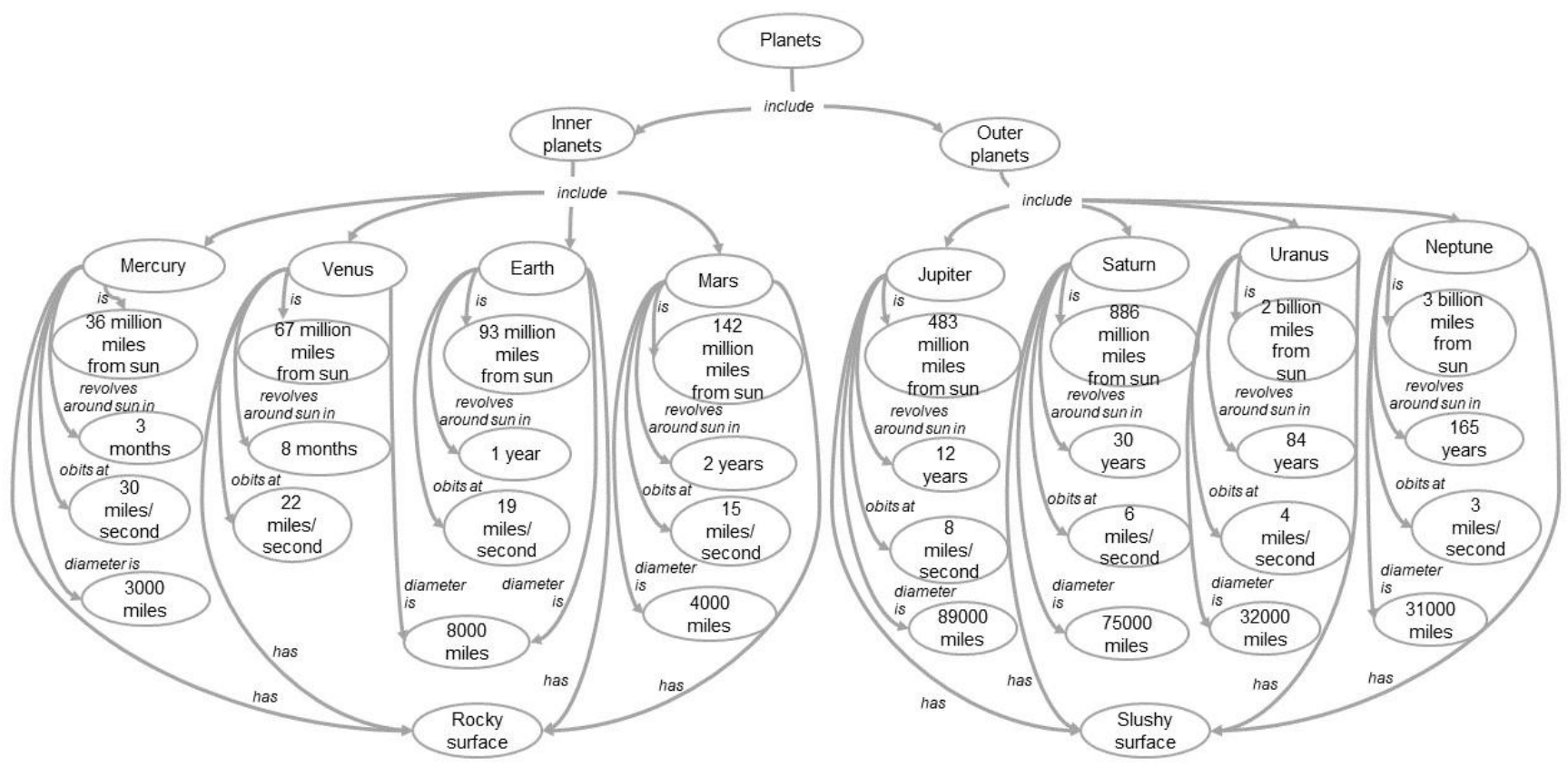

Matrices promote fact, relationship, and concept learning when compared with other displays such as outlines or text (Kauffman \& Kiewra, 2010; Kiewra et al., 1988; Kiewra et al., 1992; Robinson \& Schraw, 1994). Positive effects were found when a complete matrix was provided (Kiewra et al., 1999; Kauffman \& Kiewra, 2010; Robinson \& Kiewra, 1995) and when students filled indetails for a matrix framework containing only topics and categories (Kiewra et al., 1991; Katayama \& Robinson, 2000). To our knowledge, just one study explored training students in how to create matrices (Tompkins, 1991) and findings supported matrix training.

\subsection{Concept Map Versus Matrix}

Examining the Figure 2 matrix and the Figure 3 concept map, it is evident that the organizers are informationally equivalent.Although they contain the same information, they do not appear computationally equivalent(Larkin \& Simon, 1987). The concept map is laid out in a hierarchical structure, whereas the matrix is laid out in both a hierarchical and comparative structure. For example, although both the concept map and matrix display the hierarchical relationships showing which planets are inner planets and which are outer planets, only the matrix is structured for easily comparing planets in terms of characteristics such as miles from sun and revolution time. The concept map looks busy and repeats common terms such as orbit speedfor each planet, thereby making it difficult and time-consuming to find implicit relationships, such as: As planets' distance from the sun increases, their revolution time increases, and their orbit speed decreases. These same relationshipsare easily derived by quickly examining the first three matrix rows.

The present study is the first to train students in matrix or concept map note taking and to examine achievement, attitude, and note-taking effects. Based on computational efficiency theory, we predicted that matrix note-taking training would produce better notes, higher achievement (especially relationship learning), and more positive attitudes than would concept map note-taking training. We also predicted that the benefits of matrix note taking might be especially pronounced when notes are reviewed, because the primary benefit of note taking is more in the review of notes than in the recording of notes (Kiewra et al., 1991; Luo et al., 2018).

\section{Method}

\subsection{Participants and Design}

One hundred and seventy-six college students enrolled in an educational psychology course were assigned randomly to one of three note-taking groups (conventional - the control group, concept map, or matrix) and one of two review groups (review or no review) resulting in these six groups: conventional/review ( $\mathrm{n}=29$ ), conventional/no review $(n=29)$, concept map/review $(n=30)$, concept map/no review $(n=31)$, matrix/review $(n=31)$, and matrix/no review $(\mathrm{n}=26)$. 
Most participants were age 19 or $20(80 \%)$, male (67\%), Caucasian (67\%), in their first two years of college (75\%), and had a cumulative grade-point average (GPA) of 3.0 or higher on a four-point scale $(67 \%)$.

\subsection{Materials}

Materials included note-taking training materials, text-based learning materials, test, and survey.

There were three sets of note-taking training materials, one for conventional note takers, one for concept map note takers, and one for matrix note takers. All three sets contained three brief training passages, the first on planets, the second on moths and butterflies, and the third on central tendency. Conventional note takers practiced taking notes in their preferred ways from the three passages in turn. Concept map and matrix note takers took notes in their preferred way for the first passage on planets and were then shown an alternative form of note taking (concept map, Figure 2; or matrix, Figure 3) for that material along with information on (a) why this alternative form of note taking is better than conventional note taking (leads to more complete and organized notes vital for fact and relationship learning) and (b) how to construct such notes. Concept map note takers were taught how to create nodes and links and to place them on a map, following the procedures of Novak (1990). Matrix note takers were shown how to identify and organize matrix topics, categories, and details. Concept map and matrix note takers practiced their respective strategies for the next two passages. After each practice attempt, they compared their notes with a completed concept map or matrix for each passage.

The learning materials were a 430 -word text about reinforcement schedules. Following an introductory paragraph, the text contained four additional paragraphs, each about one of the four schedules: fixed interval, variable interval, fixed ratio, and variable ratio. Each schedule was described with regard to definition, example, response rate, response pattern, and extinction. Thus, the text contained 20 idea units, five ideas for each of the four schedules.

The reinforcement schedules test contained 18 multiple-choice items. Six items assessed fact learning (e.g., Which schedule is associated with slow responding and pauses?), six items assessed relationship learning — understanding relationships across schedules not explicitly stated in the text (e.g., Which schedules involve rapid responding?), and six items assessed concept learning - the recognition of new reinforcement schedule examples (e.g., Every time a factory worker makes five widgets, she is paid $\$ 30$. What schedule is this?).

The survey was used to collect demographic information (i.e., age, gender, race, year in college, GPA, previous note-taking training, and prior knowledge about reinforcement schedules) using a multiple-choice format. Using a six-point Likert-like scale, the survey also assessed experiment-specific attitudes about the concept map and matrix note-taking methods in terms of effectiveness, ease of construction, enjoyment, and future use.

\subsection{Procedure}

On the same day,participants in each of six different sections of the same educational psychology course were assigned randomly to one of the six experimental groups. Following introductory remarks about the experiment's purpose (to investigate note taking) and general procedures, participants were trained in their respective note-taking method for 25 minutes. Next, they were given the reinforcement schedules text and blank paper and instructed to record notes using their trained method in preparation for a test assessing facts, relationships, and the recognition of new examples (concepts). Following text learning and note taking, about half the participants in each note-taking group were instructed to review their notes (without access to the text) for 10 minutes. The others (non-reviewers) were given a sheet of multiplication problems (e.g., 14/18 x 8/12 = ?) and instructed to answer as many as they could in 10 minutes. This was done to prevent mental review. No participants completed all the problems. Next, participants completed the test, and all finished within 10 minutes. Finally, participants completed the survey within five minutes before being debriefed and dismissed. The total time for completing the experiment was 75 minutes.

\section{Results}

Survey results indicated that participants had little experience with concept map or matrix note-taking methods and with the reinforcement schedules topic prior to the experiment. About $85 \%$ reported no previous exposure to these note-taking methods, and only about $10 \%$ reported having any previous knowledge about reinforcement schedules. Survey results were analyzed using chi-square and indicated that the three note-taking groups did not differ with respect to any of the demographic variables: age, gender, race, year in college, GPA, previous note-taking training, and prior knowledge about reinforcement schedules ( $p>.05$ for all comparisons).In terms of achievement, $3 \times 2$ ANOVAs were conducted for fact, relationship, and concept learning, respectively, where the first factor was note taking (conventional, concept map, or matrix) and the second factor was review (review or no review). Table 1 provides the means and standard deviations for the six groups. The main effect of note taking was statistically significant for relationship learning, $F(2,170)=3.01, p=.05, M S \mathrm{e}=4.86$. Conventional note takers $(M=2.59$, SD $=1.27$ ) learned more relationships than map note takers $(M=2.02, \mathrm{SD}=1.28, p=.02)$, with matrix note takers $(M=2.39, \mathrm{SD}=1.32)$ falling in between. There was also a main effect of review for relationship learning, $F(1,170)$ $=7.33, p=.01, M S e=11.86$. Reviewers $(M=2.06, \mathrm{SD}=1.24)$ learned more relationships than non- reviewers $(M$ $=2.58, \mathrm{SD}=1.32)$. No other main effects or interactions reached statistical significance. 
Table 1 Achievement Means and Standard Deviations for the Six Groups on Achievement Tests

\begin{tabular}{lllllll}
\hline & Fact & \multicolumn{3}{c}{ Relationship } & \multicolumn{2}{c}{ Concept } \\
\cline { 2 - 7 } & $M$ & SD & $M$ & SD & $M$ & SD \\
\hline Control & & & & & & \\
$\quad$ No review & 3.14 & 1.66 & 2.28 & 1.31 & 2.17 & 1.56 \\
$\quad$ Review & 2.79 & 1.59 & 2.90 & 1.18 & 2.38 & 1.64 \\
Concept map & & & & & & \\
$\quad$ No review & 2.58 & 1.41 & 1.90 & 1.33 & 2.29 & 1.27 \\
$\quad$ Review & 2.90 & 1.86 & 2.13 & 1.25 & 2.33 & 1.52 \\
Matrix & & & & & & \\
$\quad$ No review & 3.27 & 1.89 & 2.00 & 1.06 & 2.00 & 1.39 \\
$\quad$ Review & 3.45 & 1.80 & 2.71 & 1.44 & 2.52 & 1.46 \\
\hline
\end{tabular}

Notes were scored for completeness (all three note-taking groups) by two independent raters $(\alpha=.87)$. Completeness scores were derived by assigning 2 points if notes were complete (contained all idea units), 1 point if notes were partially complete (contained some idea units), and 0 points if notes were missing (contained zero idea units) for each of the five information categories (definition, example, response rate, response pattern, and extinction) across the four reinforcement schedules. Thus, completeness scores could range from $0-10$. The three note-taking groups differed in note completeness, $F(2,170)=4.50, p=.01, M S e=7.07$. Matrix note takers $(M=7.12, \mathrm{SD}=2.52)$ recorded more complete notes than both the conventional $(M=5.98, \mathrm{SD}=2.40, p=.02)$ and concept map notetaking groups $(M=5.84, \mathrm{SD}=2.56, p=.01)$.

Notes were also scored by two independent raters $(\alpha=.92)$ for training implementation (concept map and matrix groups only) to determine if participants successfully created concept map or matrix notes for the reinforcement schedules text as instructed during training. Training implementation scores were derived by assigning 2 points if the method was fully used, 1 point if it was partially used, and 0 points if it was not used. Matrix note takers $(M=$ $1.48, \mathrm{SD}=0.81)$ implemented their trained method more successfully than did concept map note takers $(M=0.97$, $\mathrm{SD}=0.71), F(1,113)=13.30, p=.01, M S \mathrm{e}=7.76)$.

Correlations between achievement scores (fact, relationship, and concept) and note-taking indices (completeness and training implementation) were also derived and are presented in Table 2. As can be seen, both note-taking indices were positively correlated with fact and relationship scores.

\section{Table 2 Correlations for Achievement (1-3) and Note-taking (4-5) Variables}

Concept map and matrix groups' attitudes about their note-taking methods were also compared. As can be seen in Table 3, matrix note takers rated their note-taking method higher than did concept map note takers for all four factors: effectiveness $(t(115)=-0.85, p=.01)$, ease of construction $(t(115)=-1.12, p=.01)$, enjoyment $(t(115)=$

\begin{tabular}{llllll}
\hline & 1 & 2 & 3 & 4 & 5 \\
\hline 1. Fact & - & & & & \\
2. Relationship & $.40^{* *}$ & - & & & \\
3. Concept & .06 & $.35^{* *}$ & - & - & \\
4. Completeness & $.35^{* *}$ & $.20^{* *}$ & .08 & $.61^{* *}$ & - \\
5. Training & $.26^{* *}$ & $.30^{* *}$ & .17 & & \\
Implementation & & & & &
\end{tabular}

\footnotetext{
$* * \mathrm{p}<.01$

$-0.68, p=.01)$, and future use $(t(115)=-0.85, p=.01)$.
} 
Table 3 Participant's Attitudes about Note-taking Methods

\begin{tabular}{lllll}
\hline & \multicolumn{3}{l}{ Concept map } & Matrix \\
\cline { 2 - 5 } & $M$ & SD & $M$ & SD \\
\hline Effectiveness & 4.00 & 1.23 & 4.68 & 1.11 \\
$\begin{array}{l}\text { Ease of } \\
\text { construction }\end{array}$ & 3.02 & 1.44 & 4.20 & 1.29 \\
Enjoyment & 3.07 & 1.54 & 3.86 & 1.35 \\
Future use & 2.69 & 1.59 & 4.02 & 1.42 \\
\hline
\end{tabular}

\section{Discussion}

The present study was the first to train college students in one of two well researched note-taking methods: concept map or matrix, and to compare their achievement on various learning outcomes with or without note review. The present study also investigated the notes students produced and attitudes about their note-taking methods.

Although matrix note takers did not achieve more than concept map note takers over all or particularly following note review as predicted, there were several findings favoring matrix note taking over concept map note taking. First, conventional note takers achieved more than concept map note takers, but not matrix note takers, on relationship items. This finding is especially telling because the primary purpose of a concept map is relationship learning(Nesbit \& Adesope, 2006). Second, matrix notes were more complete than concept map notes. Note completeness is important because it was positively correlated with achievement in the present study and in previous studies (Jairam\& Kiewra, 2010; Kiewra, 1985; Nyeet al., 1984; Peverly et al., 2014). Third, the quality of the matrix notes created was better than the quality of the concept map notes created as measured by participants' ability to implement note-training procedures. As was true with previous studies (Swart,1994; Tsenget et al., 2007), students had difficulty producing concept maps as trained. Our informal observations confirmed that concept maps often lacked or misplaced important nodes and links, thereby obscuring potential relationships. Meanwhile, those creating matrix notes were adept at noting and arranging matrix topics, categories, and details. Last, matrix note takers, relative to concept map note takers, had morepositive attitudes about note-taking methods. Matrix note takers found their note-taking method more effective, easier to use, more enjoyable, and more likely to be used in future learning tasks.

In conclusion, concept map notes were problematic on all counts. Twenty-five minutes of training were not sufficient to help students create complete and high-quality concept maps. One must wonder, though, whether even well-designed concept maps, like that in Figure 3, can ever be maximally effective, as the concept map structure seems to lack computational efficiency (Larkin \& Simon, 1987), especially with regard to making comparisonssuch as those among planets. Based on our findings, we counsel practitioners to be cautious in their use of concept mapping, especially for comparative material.Matrix notes, because of their completeness, comparative structure, and students' positive attitudes about them, seem a better choice. Finally, we recommend that researchers continue to investigate the relative merits of concept map and matrix note taking, under varying instructional conditions.

\section{References}

Asan, A. (2007). Concept mapping in science class: A case study of fifth grade students. Educational Technology \& Society, $10(1), 186-195$.

Anderson-Inman, L., \&Zeitz, L. (1993). Computer-based concept mapping: Active studying for active learners. The Computing Teacher, 21, 6-11.

Eppler, M. J. (2006). A comparison between concept maps, mind maps, conceptualdiagrams, and visual metaphors as complementary tools for knowledge constructionand sharing. Information Visualization, 5(3), 202 210.https://doi.org/10.1057/palgrave.ivs.9500131

Gravett, S.J., \&Swart, E. (1997). Concept mapping: a tool for promoting and assessing conceptual change. SAJHE/SATHO, 11(2), 122-126. https://doi.org/10.1002/sce.10127

Hall, R. H., Dansereau, D. F., \& Skaggs, L. P. (1992). Knowledge maps and the presentation of related information domains. The Journal of Experimental Education, 61(1), 5-18. https://doi.org/10.1080/00220973.1992.9943845

Hall, R. H., \& O'Donnell, A. (1996). Cognitive and affective outcomes of learning from knowledge maps. Contemporary Educational Psychology, 21(1), 94-101. https://doi.org/10.1006/ceps.1996.0008 
Horton, P. B., McConney, A. A., Gallo, M., Woods, A. L., Senn, G. J., \& Hamelin, D. (1993). An investigation of the effectiveness of concept mapping as an instructional tool. Science Education, 77(1), 95-111. https://doi.org/10.1002/sce.3730770107

Jairam, D., \& Kiewra, K. A. (2010). Helping students soar to success on computers: An investigation of the SOAR study method for computer-based learning. Journal of Educational Psychology, 102(3), 601-614. https://doi.org/10.1037/a0019137

Jairam, D., Kiewra, K. A., Kauffman, D. F., \& Zhao R. (2011). How to study amatrix.Contemporary Educational Psychology, 37(2), 128-135. https://doi.org/10.1016/j.cedpsych.2011.10.003

Jegede, O. J., Alaiyemola, F. F., \& Okebukola, P. A. O. (1990). The effect of concept mapping on students' anxiety and achievement in biology. Journal of Research in Science Teaching, 27(10), 951-960. https://doi.org/10.1002/tea.3660271004

Jiang, X., \&Grabe, W. (2007). Graphic organizers in reading instruction: Research findings and issues. Reading in a Foreign Language, 19, 34-55.

Katayama, A. D., \& Robinson, D. H. (2000). Getting students "partially" involved in note-taking using graphic organizers. The Journal of Experimental Education, 68(2), 119-133. https://doi.org/10.1080/00220970009598498

Katayama, A. D., Robinson, D. H., Devaney, T., \& Dubois, N. F. (1997, March 24-28). Theinteraction of study materials and spaced review on transfer and relational learning [Paper presentation]. American Educational Research Association Annual Meeting, Chicago, IL,United States.

Kauffman, D. F., \& Kiewra, K. A. (2010). What makes a matrix so effective? An empirical test of the relative benefits of signaling, extraction, and localization. Instructional Science, 38(6), 679-705. https://doi.org/10.1007/s11251-009-9095-8

Kiewra, K. A. (1985). Investigating notetaking and review: A depth of processing alternative. Educational Psychologist, 20(1), 23-32. https://doi.org/10.1207/s15326985ep2001_4

Kiewra, K. A. (2012). Using Graphic Organizers to Improve Teaching and Learning. The IDEA Center. https://www.ideaedu.org/Portals/0/Uploads/Documents/IDEA\%20Papers/IDEA\%20Papers/PaperIDEA_51 .pdf

Kiewra, K. A., Dubois, N. E, Christian, D., \& McShane, A. (1988). Providing study notes: Comparison of three types of notes for review. Journal of Educational Psychology, 80(4), 595-597. https://doi.org/10.1037/0022-0663.80.4.595

Kiewra, K. A., DuBois, N. F., Christian, D., McShane, A., Meyerhoffer, M., \&Roskelley, D. (1991). Note-taking functions and techniques. Journal of Educational Psychology, 83(2), 240-245. https://doi.org/10.1037/0022-0663.83.2.240

Kiewra, K. A., Kauffman, D. F., Robinson, D. H., DuBois, N. F., \& Staley, R. K. (1999). Supplementing floundering text with adjunct displays. Instructional Science, 27(5), 373-401. https://doi.org/10.1023/A:1003270723360

Kiewra, K. A., Robinson, D., Dubois, N., \& Staley, R. (1992, April). Outline versus matrix representations: Memory, integration, and application effects[Paper presentation]. American Educational Research Association Annual Meeting, San Francisco, CA, United States.

Larkin, J. H., \& Simon, H. A. (1987). Why a diagram is (sometimes) worth ten thousand words. Cognitive Science, 11(1), 65-99.https://doi.org/10.1111/j.1551-6708.1987.tb00863.x

Lehman, J. D., Carter, C., \&Kahle, J. B. (1985). Concept mapping, vee mapping, and achievement: Results of a field study with black high school students. Journal of Research in Science Teaching, 22(7), 663-673. https://doi.org/10.1002/tea.3660220706

Luo, L., Kiewra, K. A., Flanigan, A. E., \&Peteranetz, M. S. (2018). Laptop versus longhand note taking: Effects on lecture notes and achievement. Instructional Science, 46(6),947-971.https://doi.org/10.1007/s11251-0189458-0

Nesbit, J. C., \& Adesope, O. O. (2006). Learning with concept and knowledge maps: A meta-analysis. Review of Educational Research, 76(3), 413-448.

Nicoll, G., Francisco, J. S., \& Nakhleh, M. (2001). An investigation of the value of using concept maps in general chemistry. Journal of Chemical Education, 78(8), 1111-1117. https://doi.org/10.1021/ed078p1111

Novak, J. D. (1990). Concept maps and vee diagrams: Two metacognitive tools to facilitatemeaningful learning. Instructional Science, 19(1), 29-52.https://doi.org/10.1007/bf00377984

Novak, J.D., \&Gowin, B. (1988). Aprendiendo a aprender. Martínez Roca.

Nye, P. A., Crooks, T. J., Powley, M., \& Tripp, G. (1984). Student note-taking related to university examination performance. Higher Education, 13(1), 85-97. https://doi.org/10.1007/bf00136532

Peverly, S. T., Garner, J. K., \&Vekaria, P. C. (2014). Both handwriting speed and selective attention are important to lecture note-taking. Reading and Writing, 27(1), 1-30. https://doi.org/10.1007/s11145-013-9431-x

Qarareh, A. O. (2010). The effect of using concept mapping in teaching on the achievement of fifth graders in science. Studies on Home and Community Science, 4(3), 155-160. 
Robinson, D. H., \& Kiewra, K. A. (1995). Visual argument: Graphic organizers are superior to outlines in improving learning from text. Journal of Educational Psychology, 87(3), 455-467. https://doi.org/10.1037/0022-0663.87.3.455

Robinson, D. H., \& Schraw, G. (1994). Computational efficiency through visual argument: Dographic organizers communicate relations in text too effectively? Contemporary Educational Psychology, 19(4), 399-415. https://doi.org/10.1006/ceps.1994.1029

Robinson, D. H., \& Skinner, C. H. (1996). Why graphic organizers facilitate search processes: Fewer words or computationally efficient indexing? Contemporary Educational Psychology, 21(2), 166-180. https://doi.org/10.1006/ceps.1996.0014

Romero, C., Cazorla, M., \& Buzon, O. (2017). Meaningful learning using concept maps as a learning strategy. Journal of Technology and Science Education, 7(3), 313-332. https://doi.org/10.3926/jotse.276

Schmid, R. F., \& Telaro, G. (1990). Concept mapping as an instructional strategy for high school biology. The Journal of Educational Research, 84(2), 78-85.https://doi.org/10.1080/00220671.1990.10885996

Swart, R. E. (1994). Die opleiding van die opvoedkundige sielkundige as reflektiewe praktisyn [Unpublished doctoral dissertation]. Rand Afrikaans University.

Tompkins, R. S. (1991). Teaching a cognitive learning strategy: Can teachers-in-training assist middle school students to utilize a matrix technique to form comparisons and contrasts?[Abstract]

Tseng, S. S., Sue, P. C., Su, J. M., Weng, J. F., \& Tsai, W. N. (2007). A new approach for constructing the concept map. Computers \& Education, 49(3), 691-707.https://doi.org/10.1016/j.compedu.2005.11.020

Willerman, M., \& Mac Harg, R. A. (1991). The concept map as an advance organizer. Journal of Research in Science Teaching, 28(8), 705-711. https://doi.org/10.1002/tea.3660280807 